\title{
Experimental investigation into the feasibility of using a variable conductance heat pipe for controlled heat release from a phase-change material thermal store
}

\section{R. Law ${ }^{1 *}$, D. A. Reay ${ }^{2}$, A. Mustaffar ${ }^{1}$, R. J. McGlen ${ }^{3}$, C. Underwood ${ }^{4}$, B. Ng $^{4}$}

${ }^{1}$ School of Engineering, Newcastle University, NE1 7RU, UK

${ }^{2}$ David Reay and Associates, PO Box 25, Whitley Bay, NE26 1QT, UK

${ }^{3}$ Aavid Thermacore Europe Ltd, 12, Wansbeck Business Park, Ashington, Northumberland NE63 $8 Q W$, UK

${ }^{4}$ Department of Mechanical and Production Engineering, Wynn Jones Building, Northumbria University, Newcastle upon Tyne NE1 8ST, UK

* Corresponding author. Email richard.law2@ncl.ac.uk

\section{Abstract}

Traditional heat storage uses large water tanks, with wide operating temperature differentials that restrict their use with heat pumps and Stirling engine DCHP systems. In contrast, the system developed under the 'THERMAC' project uses phase change materials (PCMs) for thermal storage to reduce system size, with a self-regulating, variable conductance heat pipe (VCHP) to control heat output. The VCHP is a heat pipe whose condenser is linked to a reservoir of non-condensable gas - in this case argon. Small temperature gradients expand or contract the argon along the condenser, so that it acts as a thermal switch by controlling the active length of the condenser.

The study was successful in its main objective of demonstrating the basic technical feasibility of (i) Erythritol PCM as a means of heat storage (ii) over-coming the PCM's low thermal conductivity by using fins on the VCHP, and, (iii) a VCHP as a means of controlling the thermal output of the PCM storage system, thereby increasing their overall efficiency.

Recommendations are made for further development of the 'THERMAC' concept.

\author{
Abbreviations \\ BSRIA - Building Services Research and Information Association \\ DCHP - Domestic Combined Heat and Power \\ DHW - Domestic Hot Water \\ HP - Heat Pump \\ mCHP - Micro-Combined Heat and Power \\ NCG - Non Condensable Gas \\ PCM - Phase Change Material \\ TES - Thermal Energy Storage
}

THERMAC - Thermal Management Controller for Domestic Micro-Generation Systems 
TSB - Technology Strategy Board

VCHP - Variable Conductance Heat Pipe

\section{Introduction}

\subsection{Domestic Thermal Storage}

Domestic boilers, heat pumps (HPs), combined heat and power (DCHP), and electrical heaters all need thermal storage for a variety of reasons, including but not limited to:

- Tariff optimisation - storing energy at low tariffs for use when the tariff is high.

- Peak lopping - particularly in DCHP systems, the ability to cut DCHP size by eliminating major peaks and troughs in heat demand.

- Buffering - particularly in DCHP and HPs, reducing the number of daily start-ups to improve overall efficiency by operating for longer periods in a true steady state. In air source heat pumps this concept may be extended to operating when air temperature is at its highest (when space heating typically is not needed).

- Load management - storing energy to alleviate demands on the energy supply infrastructure.

Traditional heat storage uses large water tanks, with wide operating temperature differentials that restrict their use with heat pumps and Stirling DCHP systems, the most common thermal energy storage (TES) system. Other heat stores involve a solid as the 'core' of the store, or employ phase change materials (PCMs) - the latter normally being associated with materials that transform from liquids to solids and vice-versa. Solid heat stores are widely used in some building applications, and are also popular as 'compact' storage radiators (or convectors) in domestic heating systems, together with liquid-based convectors. The domestic hot water storage tank, (many of which were removed with the advent of condensing boilers) is also regaining attention as dual-source heating systems (such as gas-boiler and solar thermal) grow in popularity (BSRIA, 2017).

PCMs present a potentially low-volume, low-mass solution to storing relatively large amounts of heat. Figure 1 below shows the relative storage mass and volume for three storage options: solid rock (sensible heat storage, based on a $70^{\circ} \mathrm{C} \Delta \mathrm{T}$ ), liquid water (sensible heat storage, based on a $70^{\circ} \mathrm{C} \Delta \mathrm{T}$ ) and a typical PCM (latent heat storage - data based on that of Erythritol, the PCM chosen for the pilot scale test rig in this study). This highlights the potential of PCMs for use in compact heat stores, as they can require less than a third of the mass and volume of water storage systems. 


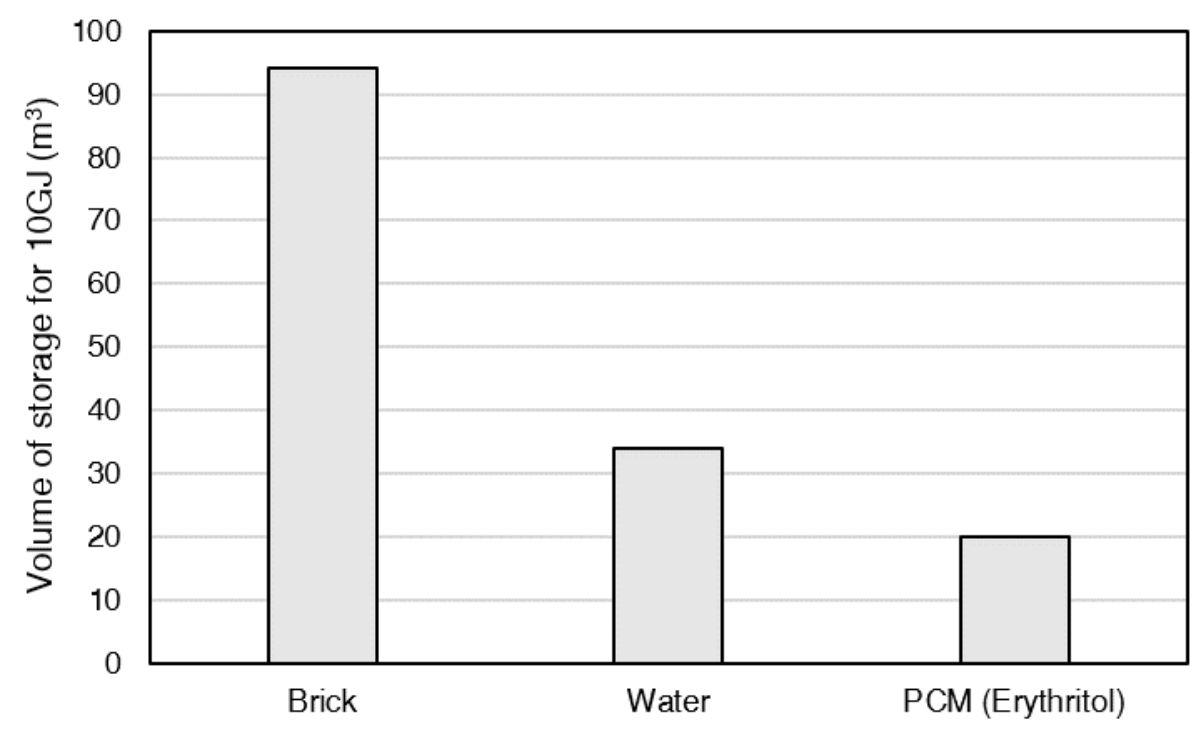

Figure 1. Relative volume $\left(\mathrm{m}^{3}\right)$ required for three thermal energy storage systems to store 10GJ of heat

However, the development of PCM stores has been hindered to date by a number of technological factors, and widely adopted commercial products, with a few exceptions, have been slow to enter the market. These factors include:

- Inherently low thermal conductivity leading to sluggish heat transfer in and out of the store. This can be mitigated against by increasing heat transfer area by including a greater number of heat exchanger tubes, for example, which will also lower the transport distance across the various sections of the store. However, this removes active volume from the store, hence lowering the net energy density and removing a key design advantage of PCM systems.

- Short life of some PCMs, in particular when subjected to many thermal heating and cooling cycles. In conjunction with this there are also few reliable long-term data on the life of a range of PCMs.

- Potential corrosive nature of some PCMs, particularly those based upon salts.

Much useful data on the above are discussed by Cabeza et al (2011) and Dincer and Rosen (2002).

\subsection{Advantages of heat pipes in thermal stores}

Heat pipes are most commonly passive, two-phase, heat transfer devices which can be used to transport relatively large heating duties under near isothermal operation. Superficially, heat pipes provide a good solution for rapid discharge of heat from thermal stores, and, when transferring heat in the opposite direction, they could be used to charge the thermal store (Amini et al, 2017). However, the standard heat pipe design does not allow controlled discharge of heat as the operation is fully passive.

A potentially massive use of heat pipes in conjunction with thermal stores has been examined in depth in Australia, (Khalifa et al, 2014), where the use of solar concentrators to generate electricity necessitates, for constant energy supply, the storage of high grade heat to power Rankine cycle machines at night time. The proposed solution involves large stores ( $>1 \mathrm{MW})$ to supply the thermal energy to the boilers when the sun is not shining. Vasiliev and colleagues at the Luikov Institute in Minsk (Vasiliev, L.L. et al, 1992), studied heat pipes for a domestic heat storage radiator based upon thermal storage in bricks (as routinely done in the UK some decades ago using electric storage 
radiators). The simple heat pipes, linked to a fan-assisted condenser section, allowed heat to be distributed around a room when the fan was operating. Other recent research has investigated loop heat pipe integration into phase change materials for thermal management of electronic devices (Zhao et al, 2016), while Weng et al (2011) studied conventional heat pipes for electronics temperature control. A decade earlier Huangfu et al (2007) looked at the control of an internal combustion engine heat removal rate using a variable conductance heat pipe, and Ampofo et al (2004) have successfully tested heat pipes to cool the London underground using the surrounding earth as the source of 'coolth'. Moving close to commercialisation, Amini et al (2017) examined several potential uses for heat pipe-thermal store combinations in industrial applications. Built environment applications have been hindered by capital costs (often the cost of large PCM volumes), but the work of Turnpenny et al at Nottingham University in the UK, for storing 'coolth' in a PCM overnight for cooling an office during summertime, by releasing the stored energy using heat pipes and forced air convectors in the daytime was successfully demonstrated. Boo et al (2011) reported on the numerical analysis of a PCM with embedded heat pipes, one of several papers that considered theoretical analyses of the concept.

The variable conductance heat pipe (VCHP), sometimes called a specific variant the gas-controlled or gas-loaded heat pipe, has a unique feature that sets it apart from other types of heat pipe. This is its ability to maintain a device mounted at the evaporator at a near constant temperature, independent of the amount of power being generated by the device.

The temperature control functions of a gas-buffered heat pipe were first examined as a result of noncondensable gas generation within a sodium/stainless steel basic heat pipe. It was observed (Wyatt, 1965) that as heat was put into the evaporator section of the heat pipe, the hydrogen generated was swept to the condenser section. An equilibrium situation shown in Figure 2 was reached.

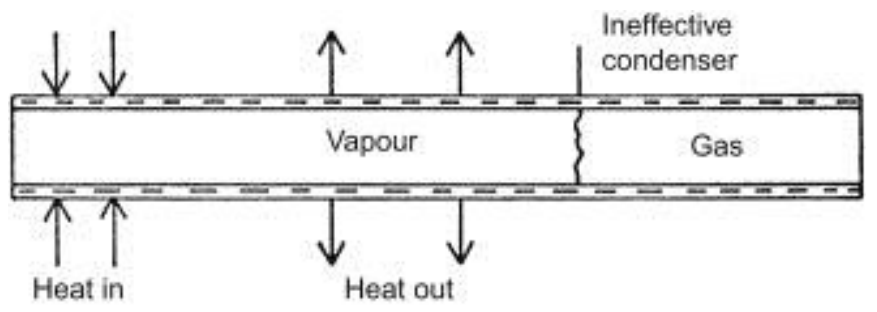

Figure 2. The equilibrium situation reached when Wyatt observed a gas blockage in his heat pipe condenser section.

Much of the subsequent work on heat pipes containing non-condensable or inert gases has been in developing means for controlling the positioning of the gas front, and in ensuring that the degree of temperature control achievable is sufficient to enable components adjacent to the evaporator section to be operated at essentially constant temperatures, independent of their heat dissipation rates, over a wide range of powers.

The first extension of the simple form of gas-buffered pipe was the addition of a reservoir downstream of the condenser section (visible in Figure 3 based upon integration of the THERMAC concept with a mCHP system). This was added to allow all the heat pipe length to be effective when the pipe was operating at maximum capability and to provide more precise control of the vapour temperature. The reservoir could also be conveniently sealed using a valve, (Reay et al, 2015). 


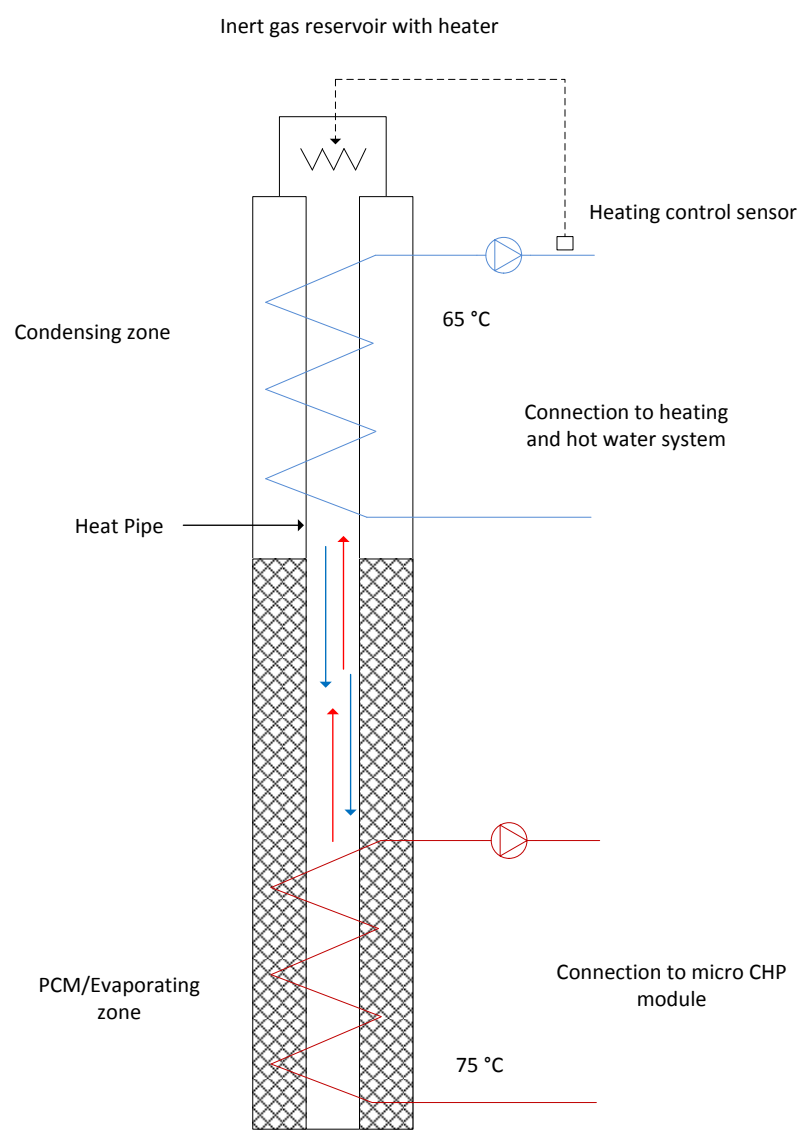

Figure 3. The Variable Conductance Heat Pipe linked to a Micro CHP Unit: one concept suggested during the THERMAC project

\subsection{The THERMAC project and aims}

The THERMAC project (Thermal Management Controller for Domestic Micro-Generation Systems) was an Innovate-UK/EPSRC (TSB Grant Agreement 131510) project whereby the objectives were to perform a feasibility study into the concept of a PCM-VCHP thermal store which is both compact (due to PCM storage material and finning of store) and able to control the rate of discharge (due to use of VCHP in discharge circuit). The aims of this experimental study were as follows:

1. To demonstrate the technical feasibility of the PCM Erythritol as a suitable means of domestic heat storage.

2. To overcome the inherent problems with low thermal conductivity of PCM materials by finning the evaporator section of the VCHP and the walls of the thermal store.

3. To demonstrate the VCHP as an effective means of controlling the heat release from the thermal store, with a high turn-down ratio.

It is generally recognised that many PCMs, particularly for the temperature range under investigation here, have a low thermal conductivity. This there are substantial benefits in using methods to (a) improve the thermal conductivity of the PCM (either by adding metal particles or, as in this case, finning the inside of the container and inserting a heat pipe) and (b) to manage the heat removal rate. The impact on energy efficiency is reflected in the fact that there are no, or much fewer, 'dead spots' in the PCM body, so all the stored heat is usefully contributing to the required duty. By using the VCHP 
to control the heat removal rate to match demand, it can be ensured that less heat is delivered at times when it may not be needed.

Following on from this comments for future development are made with specific regards to how the THERMAC concept may be integrated with common domestic heating (particularly $\mathrm{mCHP}$ ) systems.

\section{The THERMAC Concept}

The overall aim of the THERMAC concept is to create a compact, PCM-based, heat store which can be charged over a specific period of time (e.g. during non-peak electricity hours for electric heaters, during daytime for air-source heat pump systems or during a scheduled running period for a $\mathrm{mCHP}$ Stirling engine system to reduce number of start-ups per day) and controllably discharged via a VCHP according to heating demand. When heating demand is at the maximum, the pressure of the inert gas store will be at a minimum, hence removing the gas front from the active condenser region and allowing maximum heat discharge. As heat demand falls, the pressure in the store will gradually be increased (via a small electric heater) to move the gas front, reducing the active area of the condenser.

\subsection{Pilot-Scale Rig}

A pilot scale storage system of approx. $2 \mathrm{kWh}$ thermal capacity was developed for use in this initial feasibility test. For simplicity of operation, the rig was designed to be charged by electric band heaters (positioned on the walls of the store), while a water tank with temperature control was used to simulate a domestic hot water system during discharge. Erythritol was used as the storage medium, due to its relatively high heat of fusion, high melting point and non-toxic, non-corrosive properties. The thermal properties of Erythritol and two other considered PCMs are shown in Table 1 below.

Table 1 Properties of Erythritol compared to other PCMs considered

\begin{tabular}{|l|l|l|l|l|}
\hline Material & $\begin{array}{l}\text { Melting Point } \\
\left({ }^{\circ} \mathbf{C}\right)\end{array}$ & $\begin{array}{l}\text { Heat of } \\
\text { Fusion }(\mathbf{k J} / \mathbf{k g})\end{array}$ & $\begin{array}{l}\text { Density } \\
\left(\mathbf{k g} / \mathbf{m}^{3}\right)\end{array}$ & $\begin{array}{l}\text { Volumetric } \\
\text { storage } \\
\text { capacity } \\
\left(\mathbf{k J} / \mathbf{m}^{3}\right) \\
{\left[\begin{array}{l}\text { excluding } \\
\text { sensible heat }]\end{array}\right.}\end{array}$ \\
\hline $\begin{array}{l}\text { Salt Hydrate } \\
\text { (S117) }\end{array}$ & 117 & 169 & 1450 & 245,000 \\
\hline Paraffin Wax & 106 & 80 & 1200 & 96,000 \\
\hline Erythritol & 118 & 335 & 1390 & 465,000 \\
\hline
\end{tabular}

Erythritol's long term stability with changing temperature and container materials were tested at TWI, Cambridge, in Al alloy and Cu tube ampules. These were partially charged with desiccated Erythritol, backfilled with dry N2, dry air or moist air, sealed with silicone resin or by welding, and stored $>150^{\circ} \mathrm{C}$, higher than the target store temperature of about $130^{\circ} \mathrm{C}$, for more than 2 months, before sectioning. OEM and SEM analysis showed no significant corrosion in this period, nor did the Erythritol degrade. Silicone seals worked, but low heat input welding would ensure design lifetimes of 20 years, and ultrasonic welding was demonstrated for the Al tubes. Internal fins are needed to counter Erythritol's low thermal conductivity. Friction stir welding was demonstrated as a possible fabrication technique.

The rig consisted of the following (see also, Figures 4, 5 and 6):

- Storage tank (Figure 4). A 10 l square cross-section storage tank (to hold $13 \mathrm{~kg}$ of PCM, approx. $2 \mathrm{kWh}$ heat storage) was constructed from aluminium. The inner walls of the tank were finned 
to overcome inherent heat transfer issues apparently within PCM stores due to the low thermal conductivity of the materials. The degree of finning was determined during an extensive finite-element modelling study, the results of which are proprietary. The tank was well lagged throughout the tests, apart from at the bottom surface which may have lost heat to the laboratory floor.

- VCHP (placed in storage tank). A custom copper-water VCHP built by Aavid-Thermacore Ltd. The heat pipe was $22 \mathrm{~mm}$ in diameter, $1.23 \mathrm{~m}$ long, with roughly $50 \%$ of the length each attributed to the evaporator and condenser sections (with an insignificant adiabatic zone length). The evaporator was wicked internally (copper sinter) to aid liquid-return, and finned externally (Figure 4) to help overcome the inherent thermal conductivities issues associated with PCM stores. The condenser section was jacketed, effectively creating a simple tube-intube heat exchanger with the heat pipe condenser on the inner tube, and the simulated DHW supply on the outer tube. An argon tank was placed at the top of the store with a band heater in place to allow control of the argon-working fluid vapour interface: at $25^{\circ} \mathrm{C}$ the argon was at position 0 (i.e. full condenser length was available), at $35^{\circ} \mathrm{C}$ the argon interface was at the bottom of the condenser (i.e. zero condenser length was available). Various valves were positioned to allow isolation of the argon if/when needed. The assembled rig is shown in Figure 5 and a schematic in Figure 6.

- Instrumentation. Thermocouples were placed throughout the rig, on the heat pipe surface, the fin surfaces, at the water jacket inlet and outlets, and in the PCM tank. Rough thermocouple positions are shown in Figure 6.

- Lagging. The rig was heavily lagged to minimise heat loss as shown in Figure 5 (note: the argon tank was not lagged to allow cooling by natural convection when it was required to shift the gas front upwards towards position 0 ).

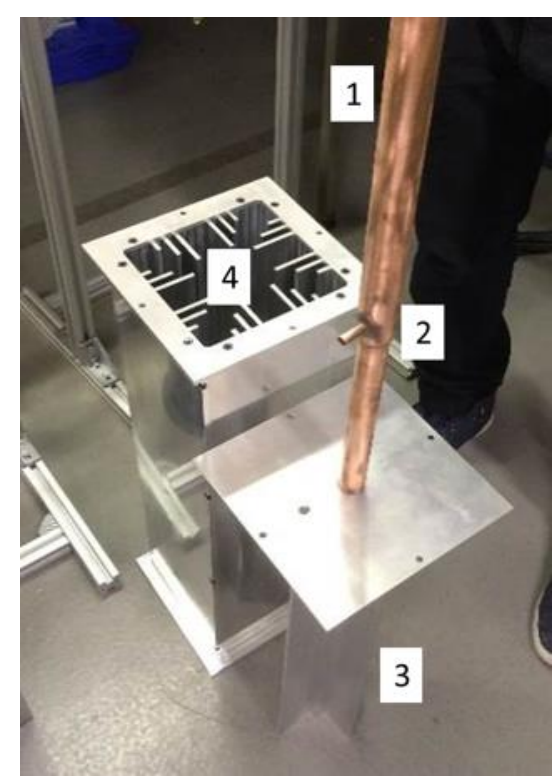

Figure 4. Photograph of the dismantled test rig. (1) Jacketed heat pipe condenser (2) Water inlet (to condenser heat exchanger) (3) Finned evaporator section (4) PCM storage tank with finned walls. 


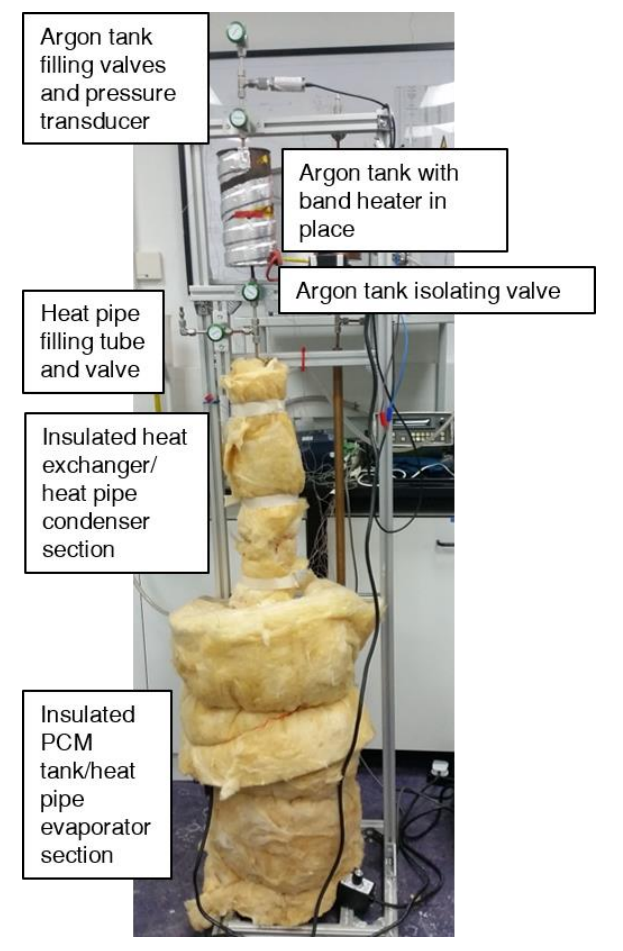

Figure 5. Assembled pilot-scale test unit

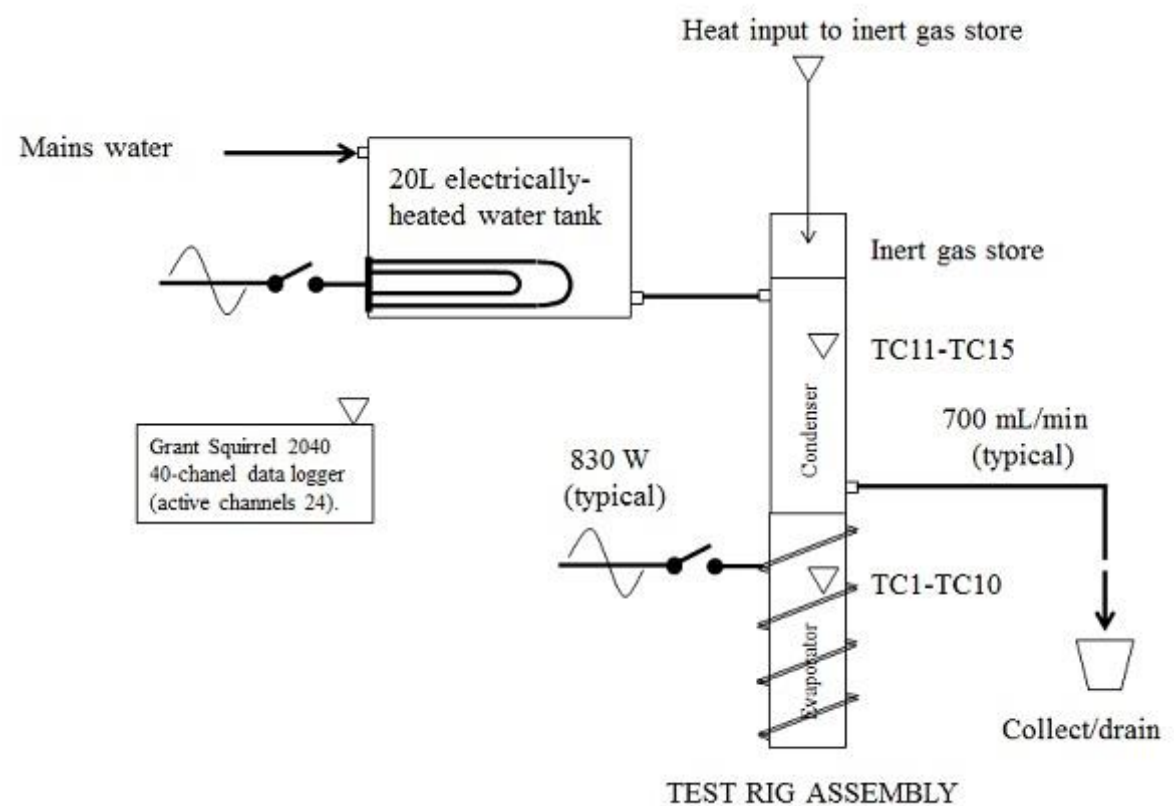

Figure 6. Schematic of test rig

\subsection{Experimental Programme}

The heat store was charged using an $830 \mathrm{~W}$ band heater for approx. 3 hours. It is noted that during the charging phase around $20 \%$ of heat was lost to the environment, mainly through the base to the laboratory floor. During discharge, a constant flow of water at $45^{\circ} \mathrm{C}$ of $650 \mathrm{ml} / \mathrm{min}$ was used. Two different discharge tests were performed: 
1. Maximum discharge rate: in this case, no variable condenser control was used and the store discharged at the maximum rate. This test was used to determine the maximum heat removal rate from the heat pipe and the total heat in the store.

2. Variable discharge rate: in this case, the argon front position was manually altered by controlling heat input into the Argon store using a band heater. This test was used to demonstrate the feasibility of the system to turn-down the rate of heat release.

During the tests, the main objectives were to demonstrate the technical feasibility of (i) Erythritol PCM as a means of heat storage for use in domestic applications (ii) overcoming the PCMs low thermal conductivity by finning of the thermal store and the VCHP evaporator (iii) the use of the VCHP as a means of controlling the thermal output of the PCM storage unit.

\section{Results and Discussion}

Figure 7a shows the fin temperature (at tip and root) for a complete charge and discharge cycle at maximum rate. As the fins were located within the PCM tank, this is a good indication of the PCM temperature within the tank. Figure $7 \mathrm{~b}$ shows the discharge heating rate vs time for the same chargedischarge cycle. During these tests, the water outlet temperature from the condenser heat exchanger was maintained above $60^{\circ} \mathrm{C}$ which is suitable for use in British standard central heating and domestic hot water applications.

(a)

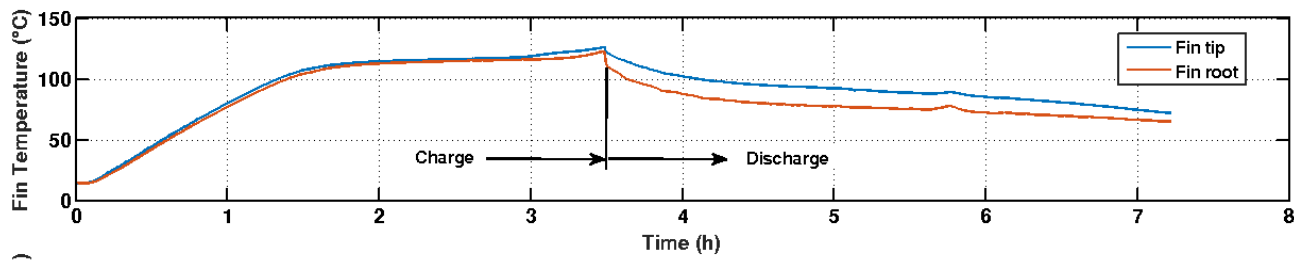

(b)

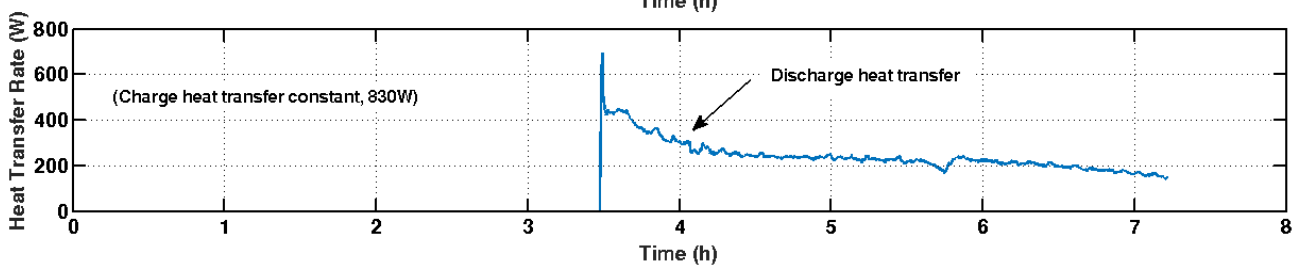

Figure 7. (a) Heat pipe evaporator fin temperature and (b) discharge heat transfer rate vs time.

Figure $7 \mathrm{~b}$ shows the mean discharge rate in the test was $249 \mathrm{~W}$, significantly lower than the heat input rate of $830 \mathrm{~W}$. Therefore, in future iterations of the rig, a need exists for better balance between the potential heat input/output maximum rates. This could potentially be achieved by optimising the fin structure of the heat pipe evaporator (the temperature difference between the fin root and tip in Figure 7a shows that the design is currently far from optimal) or by using multiple heat pipes in one PCM store.

The almost constant heat discharge rate between hours 4 and 7, however, suggests that the PCM store and heat pipe both maintained near-isothermal operation throughout the maximum discharge test which can be considered a positive result in this feasibility study. 


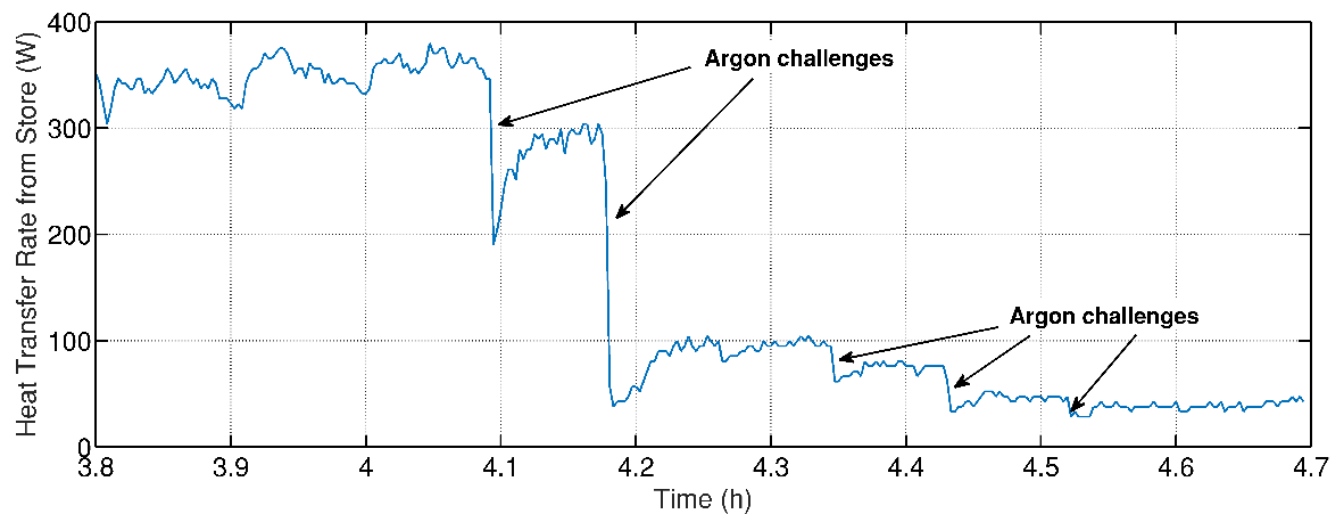

Figure 8. Heat discharge rate vs time following five Argon challenges

Figure 8 shows the results for four argon challenges into the heat pipe condenser, which were achieved by heating the Argon tank over the temperature range of $25-35^{\circ} \mathrm{C}$. The results show success in turning down the heat output from a maximum rate of $350 \mathrm{~W}$ to a minimum rate of $50 \mathrm{~W}$, a ratio of $7: 1$. This proves the feasibility of using a VCHP to control the rate of heat release from a PCM thermal store. Other observations from the study are as follows:

- For each Argon challenge, it took around 0.05 hours ( 3 minutes) for the Argon-vapour interface to stabilise and reach a new steady-state. While this is already quite rapid, this could be improved in a future iteration of the rig by using a well-designed PI (proportional-integral) controller, rather than the human control we used in this study.

- The results shown in Figure 8 show a good measure of control when turning-down the heat output. However, during the tests it was found to be near impossible to turn-up the heat output with a sufficient degree of control. This is because the rig had no means of actively reducing the temperature of the Argon store: the only cooling mechanism was by natural convection to the ambient. Therefore, any future iteration of the rig must include an active means of cooling such as a small fan or a cooling water-loop.

\section{Future Outlook}

If the THERMAC concept is to be taken forward the initial focus should be on solving the problems encountered in the initial pilot-scale trials, discussed as follows:

- A need exists for more rapid cooling of the Argon store to allow rapid retreat of the gas front. This could be achieved using active cooling (e.g. forced convection) or by reducing the volume of the store which was relatively large compared to the heat pipe condenser volume.

- Development of an automated control system for the gas front and therefore the heat released from the store.

- Optimisation of maximum heat release rate. In the existing system this was around 350W compared to an inlet heat transfer rate of $830 \mathrm{~W}$. This could be done by redesigning the tubein-tube condenser (introducing baffles, for example) or by using multiple heat pipes in a single store.

Following on from this, future development should also consider how the THERMAC concept may be integrated into different types of heating system. The pilot system would be fine as a direct replacement for electric storage heaters, but other types of heating systems have further design challenges, discussed as follows: 
- A lower temperature PCM would be required for heat pump or mCHP systems. Some salt hydrates may be suitable.

- The store would need to be designed to be able to accept heat from a fluid source, for example using a heating coil. The system described in Figure 3 is a conceptual design for a lowertemperature THERMAC-type store using a heat coil connected to a mCHP system.

- Increasing store capacity to minimise the number of start-up cycles required by heat pump or mCHP systems.

\section{Conclusions}

The THERMAC project investigated the feasibility of using a variable conductance heat pipe to control the release of heat from a thermal store containing phase change materials (Erythritol in this case). The store was designed to have extended surfaces on the wall of the heat pipe evaporator and on the wall of the thermal store to overcome inherent problems with low thermal conductivity of phase change materials.

The pilot test results from the project were positive. The heat pipe proved to be an efficient means of heat release from the store, the extended surfaces appeared to overcome any thermal conductivity issues and the manual control of the variable conductance of the heat pipe allowed a turn-down in heat output of approximately 7:1.

Recommendations are made for future development of the concept, including how the original pilot rig can be improved and how one might incorporate the store into future applications involving heat pumps and/or micro CHP systems.

\section{Acknowledgements}

The Thermac partners were: Thermacore Europe, (now Aavid Thermacore), assisted by David Reay \& Associates (DRA) - developers of the VCHP system; the University of Northumbria at Newcastle (UNN) - construction and integration of the thermal and VCHP test rigs with the DCHP system, and system trials; TWI - research into and choice of PCM; and Sustainable Engine Systems (SES) - project lead, assisted by DRA. The project was funded by Innovate-UK/EPSRC (TSB Grant Agreement 131510).

\section{References}

[1] BSRIA (2017) Global boiler market heats up as the UK is no longer the largest market. Available at: https://www.bsria.co.uk/news/article/global-boiler-market-heats-up-as-the-uk-is-no-longer-thelargest-market/ Accessed $18^{\text {th }}$ January 2018.

[2] Cabeza, L.F. et al, (2011). Materials used as PCM in thermal energy storage in buildings: A review. Renewable and Sustainable Energy Reviews 15, 1675-1695. doi:10.1016/j.rser.2010.11.018

[3] Dincer. I. and Rosen M.A. (2002). Thermal energy storage. Systems and applications. John Wiley \& Sons; New York.

[4] Amini, A. et al (2017). An investigation into the use of the heat pipe technology in thermal energy storage heat exchangers. Energy 136, 163-172. http://dx.doi.org/10.1016/i.energy.2016.02.089

[5] Khalifa A, et al (2014). A numerical and experimental study of solidification around axially finned heat pipes for high temperature latent heat thermal energy storage units. Applied Thermal Engineering 136, 163-172. http:// 


\section{dx.doi.org/10.1016/j.applthermaleng.2014.05.080.}

[6] Vasiliev, L.L.et al, (1992). Experimental device for the residential heating with heat pipe and electric heat storage blocks. Heat Recovery Systems\& CHP 12, 81-85.

[7]Zhao, J., Rao, Z., Liu, C., Li, Y. (2016). Experimental investigation on thermal performance of phase change material coupled with closed loop oscillating heat pipe (PCM/CLOHP) used in thermal management. Applied Thermal Engineering 93, 90-100

[8] Y-C. Weng, H-P. Cho, C-C. Chang, S-L. Chen. Heat pipe with PCM for electronic cooling. Applied Energy 88 (2011) 1825-1833

[9] Y. Huangfu, J.Y. Wu, R.Z. Wang, Z.Z. Xia, A. Li. Development of an experimental prototype of an integrated thermal management controller for internal-combustion-engine-based cogeneration systems. Applied Energy 84 (2007) 1356-1373.

[10] F. Ampofo, G. Maidment, J. Missenden. Underground railway environment in the UK. Part 3: Methods of delivering cooling. Applied Thermal Engineering 24 (2004) 647-659.

[11] J.H. Boo, S.K. Lee, J.K. Kim.. Numerical analysis of a thermal storage system with inserted heat pipes for medium-high temperature range. Proceedings of $10^{\text {th }}$ International Heat Pipe Symposium. Taiwan, 6-9 November, 2011.

[12] Wyatt, T. (1965). A controllable heat pipe experiment for the SE-4 satellite JHU Tech. Memo APL-SDO-1134, John Hopkins University, Appl. Phys. Lab., March 1965, AD 695433.

[13] Reay, D.A., Kew, P.A. and McGlen, R. (2015). Heat Pipes. $6^{\text {th }}$ Edition, Butterworth Heinemann, Oxford. 